\title{
Diminutive colon polyp coexisting with a large lipoma: An endoscopic 'rarity'
}

\author{
Frederick Lancet $\mathrm{MD}^{1}$, Laura E Alberti ${ }^{2}$, Juan J Alberti-Flor MD FACP ${ }^{3}$
}

\begin{abstract}
F Lancet, LE Alberti, JJ Alberti-Flor. Diminutive colon polyp coexisting with a large lipoma: An endoscopic 'rarity'. Can J Gastroenterol 2004;18(3):178.

Lipomas are the most common nonepithelial tumours of the gastrointestinal tract. In the colon, however, lipomas are uncommon. Herein we report the case of a patient who had a large colonic lipoma with an overlying bleeding diminutive colon polyp that was successfully resected using endoscopic electrocautery.
\end{abstract}

Key Words: Colon polyps; Colonic lipoma; Endoscopic resection; Intestinal bleeding

\section{Coexistence d'un minuscule polype et d'un lipome volumineux au côlon : Phénomène rare à l'endoscopie}

Les lipomes sont les tumeurs non épithéliales les plus courantes du tractus digestif. Par contre ils se forment rarement dans le côlon. Nous faisons ici état d'un cas de lipome volumineux au côlon avec surimposition d'un polype hémorragique de petite taille qui a pu être réséqué avec succès par électrocautère endoscopique.

\section{CASE PRESENTATION}

A 74-year-old man was admitted to hospital with a three-week history of intermittent rectal bleeding and anemia. Physical examination was unremarkable and pertinent laboratory tests revealed a hemoglobin of $9.8 \mathrm{~g} / \mathrm{dL}$. Colonoscopy revealed diverticulosis and a large $(2 \mathrm{~cm})$, midtransverse colon lipoma with a small polyp-like lesion on top of the lipoma (Figure 1). Endoscopic resection was performed without complications using a large snare. Histologically, a linear hemorrhagic streak was noted near the centre of the lipoma and focal areas of hemorrhage were grossly evident near the surface of the smaller polyp. Furthermore, several prominent congested blood vessels were seen within the lamina propria of the adenomatous polyp with adjacent areas of recent hemorrhage. The patient remained stable and eventually was discharged home. An office visit four weeks later failed to reveal a history of recurrent bleeding.

\section{DISCUSSION}

Lipomas are the most common nonepithelial tumours of the gastrointestinal tract (1). In the colon, however, lipomas are uncommon. Colonic lipomas tend to occur in an older population and rarely cause symptoms. Amongst the most common problems when they occur are bleeding, obstruction, perforation and intussusception.

Our patient presented with gastrointestinal bleeding and anemia, and colonoscopy revealed an endoscopic 'rarity' consisting of a large lipoma with an overlying polyp. A rare case of colonic lipoma coexisting with an overlying hyperplastic polyp was described by Radhi and Haig (2).

In the case herein reported, by removing the large colonic lipoma with the overlying adenomatous polyp, recurrent lower

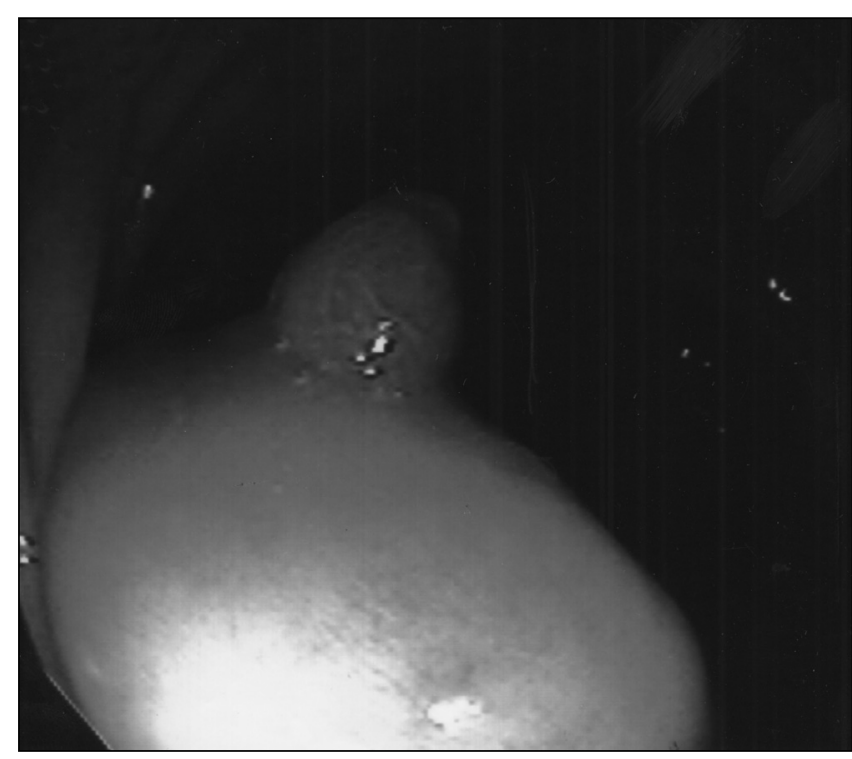

Figure 1) Endoscopic photograph of a large colonic lipoma with an overlying polyp

gastrointestinal bleeding and colon cancer were prevented. This case of a large colonic lipoma with an overlying adenomatous polyp would remain distinctly unusual and should alert the treating gastroenterologist as to this endoscopic 'rarity'.

\section{REFERENCES}

1. McGrew W, Dunn GD. Colonic lipomas: Clinical significance and management. South Med J 1985;78:877-9.

2. Radhi JM, Haig TH. Lipoma of the colon with overlying hyperplastic epithelium. Can J Gastroenterol 1997;11:694-5.

\footnotetext{
${ }^{1}$ Department of Pathology, Coral Gables Hospital, Coral Gables; ${ }^{2}$ Nova Southeastern University College of Osteopathic Medicine,

Fort Lauderdale; ${ }^{3}$ Division of Gastroenterology, Coral Gables Hospital, Coral Gables, Florida, USA

Correspondence and reprints: Dr Juan J Alberti-Flor, 2601 SW 37 Avenue, Suite 506, Miami, Florida 33133, USA. Telephone 305-446-2626,

fax 305-444-7342, e-mail AlbertiFl@aol.com
}

Received for publication September 9, 2003. Accepted November 13, 2003 


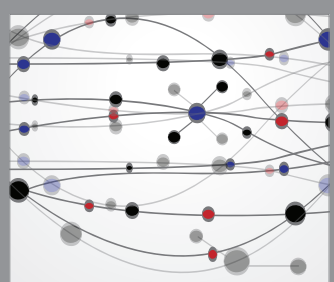

The Scientific World Journal
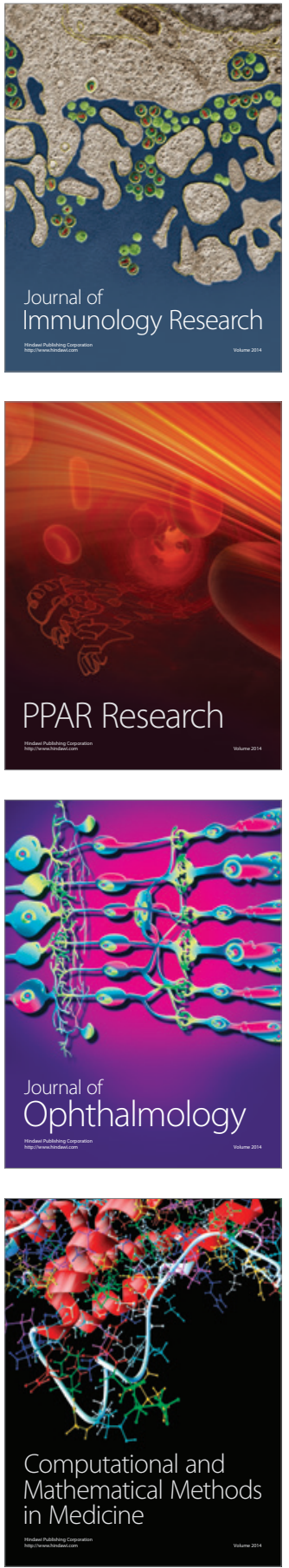

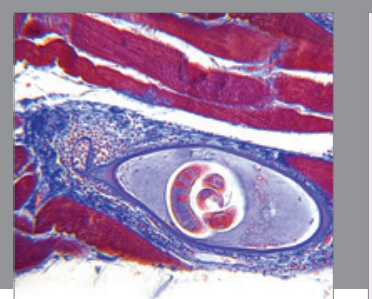

Gastroenterology Research and Practice

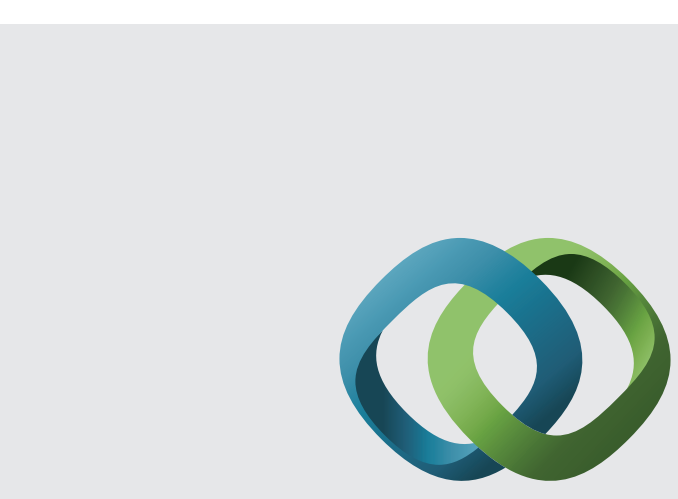

\section{Hindawi}

Submit your manuscripts at

http://www.hindawi.com
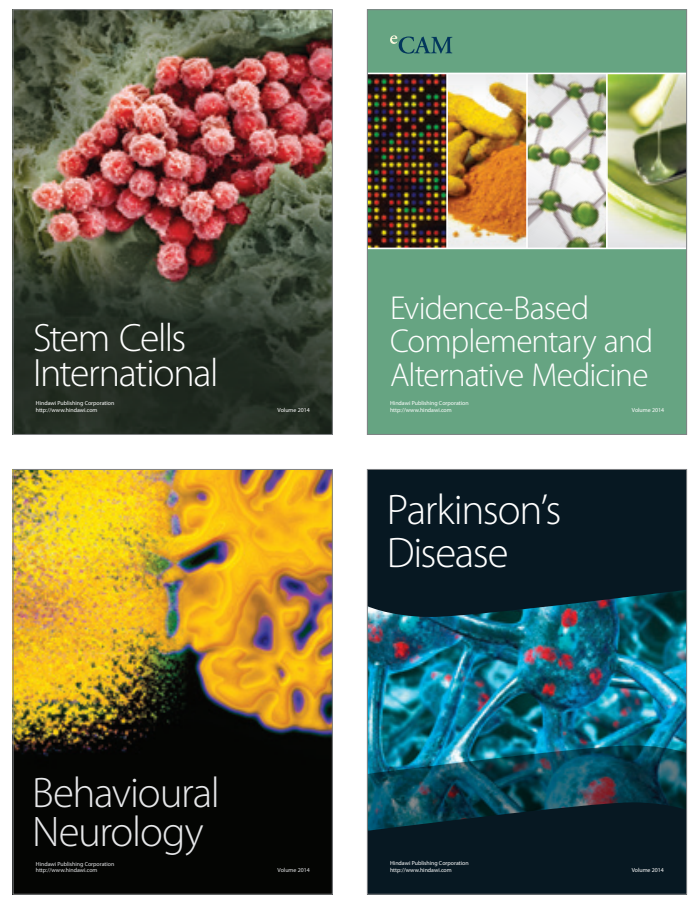
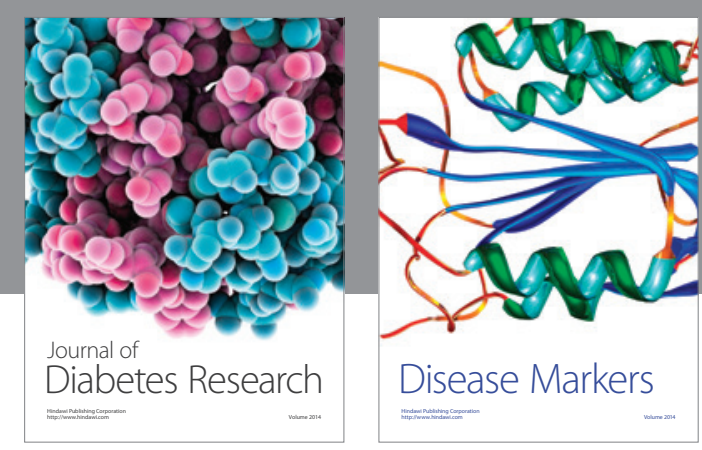

Disease Markers
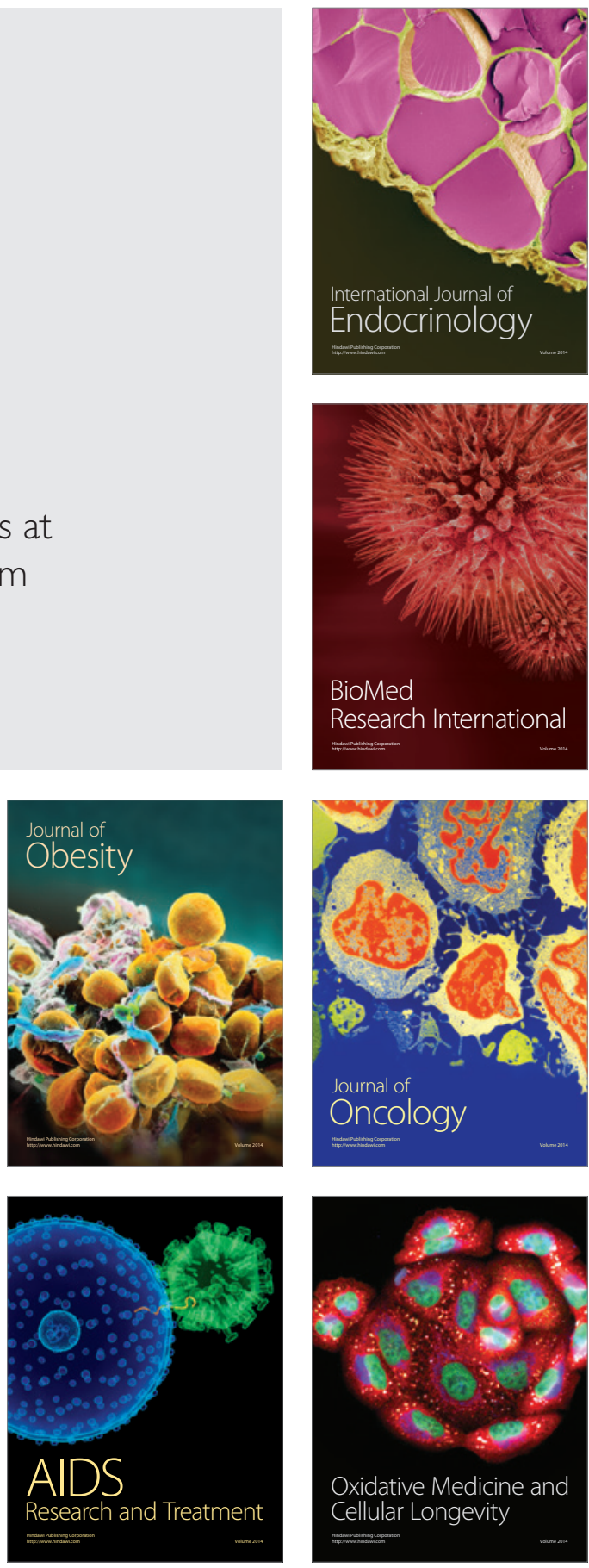